\title{
Hip Joint Osteochondroma: Systematic Review of the Literature and Report of Three Further Cases
}

\author{
Asim M. Makhdom, ${ }^{1,2}$ Fan Jiang, ${ }^{1}$ Reggie C. Hamdy, ${ }^{1}$ Thierry E. Benaroch, ${ }^{1}$ \\ Martin Lavigne, ${ }^{3}$ and Neil Saran ${ }^{1}$ \\ ${ }^{1}$ Division of Orthopaedic Surgery, Shriners Hospital for Children, Montreal Children Hospital, McGill University, \\ 1529 Cedar Avenue, Montreal, QC, Canada H3G 1A6 \\ ${ }^{2}$ Department of Orthopaedic Surgery, King Abdulaziz University, Jeddah 21589, Saudi Arabia \\ ${ }^{3}$ Division of Orthopaedic Surgery, Maisonneuve-Rosemont Hospital, University of Montreal, 5415 Assomption Boulevard, \\ Montreal, QC, Canada H1T 2M4
}

Correspondence should be addressed to Asim M. Makhdom; makhdomas@hotmail.com

Received 17 January 2014; Accepted 23 March 2014; Published 20 May 2014

Academic Editor: Christian Bach

Copyright (C) 2014 Asim M. Makhdom et al. This is an open access article distributed under the Creative Commons Attribution License, which permits unrestricted use, distribution, and reproduction in any medium, provided the original work is properly cited.

\begin{abstract}
The aim of this study is to systematically review the literature with regards to surgical treatment of patients with hip joint osteochondromas, and to report our surgical management of three paediatric patients who had femoral neck or acetabular osteochondromas in association with acetabular dysplasia. We performed a systematic review using PubMed and Embase databases for all studies that reported surgical treatments for patients with peritrochanteric or acetabular osteochondroma with or without acetabular dysplasia. We also retrospectively reviewed three patients who were diagnosed with a hip osteochondroma in association with actetabular dysplasia. These patients were known to have hereditary multiple exostoses (HME). The systematic review revealed 21 studies that met our inclusion criteria. All studies were case reports and retrospective in nature and failed to conclude a uniform treatment plan. The three reported cases illustrate successful excision of hip osteochondromas and treatment of acetabular dysplasia. Early excision of hip osteochondromas might prevent acetabular dysplasia in HME patients. Routine radiographic pelvic survey at the time of diagnosis of HME is recommended for early detection of hip osteochondromas and acetabular dysplasia in these children.
\end{abstract}

\section{Introduction}

Osteochondromas are benign osteocartilaginous primary tumours of long bones typically found in the forearm, knees, or ankles [1]. They commonly involve the metaphysis and can cause significant deformities, restriction of range of motion (ROM), persistent pain, and growth disturbance [1-3]. They may occur as a solitary lesion or as multiple lesions in the context of hereditary multiple exostoses (HME), an autosomal dominant disorder with an approximate prevalence of 1 in 50,000 in the general population $[4,5]$. Several studies in the literature have reported the occurrences of these lesions in the hip and acetabulum [6-25]. Acetabular dysplasia and coxa valga occur in approximately $25 \%$ of HME patients [5]. It has been suggested that acetabular dysplasia and femoral neck osteochondromas may independently or synergistically contribute to the increased risk of lateral subluxation of the hip
[26]. Typically, surgical intervention is considered when these features are present. However, the surgical management for such lesions remains challenging for orthopaedic surgeons as they are not commonly encountered in clinical practice. The primary aim of this study is to systematically review the literature with regards to the surgical treatment of patients with hip osteochondromas. The secondary aim is to present our surgical management for three paediatric patients who had hip subluxation secondary to femoral neck/acetabular osteochondromas in association with acetabular dysplasia.

\section{Materials and Methods}

The systematic review was performed using PubMed and Embase databases. Our search terms included "hip osteochondroma," "proximal femoral osteochondroma," "femoral 
TABLE 2: Literature review. Surgical treatments for hip osteochondroma with acetabular dysplasia in previous studies.

\begin{tabular}{|c|c|c|c|c|c|c|c|}
\hline Author and date & $\begin{array}{c}\text { Number of } \\
\text { patients }\end{array}$ & Age & Gender & $\begin{array}{l}\text { Location of the } \\
\text { lesion }\end{array}$ & Procedure & $\begin{array}{c}\text { Follow-up } \\
\text { period }\end{array}$ & Complications \\
\hline \multirow{2}{*}{$\begin{array}{l}\text { Malagón } 2001 \\
\text { [5] }\end{array}$} & \multirow[t]{2}{*}{ Two } & $\begin{array}{l}\text { Nine } \\
\text { years }\end{array}$ & Male & $\begin{array}{l}\text { Medial femoral } \\
\text { neck. }\end{array}$ & $\begin{array}{l}\text { (1) Right femoral varus } \\
\text { osteotomy. } \\
\text { (2) Bilateral staged Chiari } \\
\text { procedures. }\end{array}$ & Four years & $\begin{array}{l}\text { Persistent hip pain and } \\
\text { limited } \mathrm{ROM}^{1} \text {. }\end{array}$ \\
\hline & & $\begin{array}{l}\text { Eight } \\
\text { years }\end{array}$ & Male & $\begin{array}{l}\text { Femur neck (the } \\
\text { exact location is } \\
\text { not specified). }\end{array}$ & $\begin{array}{l}\text { Bilateral proximal varus femur } \\
\text { osteotomy. }\end{array}$ & $\begin{array}{c}\text { Not } \\
\text { specified }\end{array}$ & Not specified. \\
\hline $\begin{array}{l}\text { Felix et al., } 2000 \\
{[10]}\end{array}$ & One & 12 years & Female & $\begin{array}{l}\text { Bilateral medial } \\
\text { femoral neck. }\end{array}$ & $\begin{array}{l}\text { (1) Bilateral staged excision } \\
\text { through the posterior } \\
\text { approach and } \mathrm{VDRO}^{2} \text {. } \\
\text { (2) Bilateral staged steel } \\
\text { osteotomy. }\end{array}$ & Two years & Not reported. \\
\hline $\begin{array}{l}\text { Shinozaki et al., } \\
1998 \text { [16] }\end{array}$ & One & 30 years & Male & $\begin{array}{l}\text { Femoral neck } \\
\text { (the exact } \\
\text { location is not } \\
\text { specified). }\end{array}$ & $\begin{array}{l}\text { Excision through the anterior } \\
\text { iliofemoral and posterior } \\
\text { approach. Rotational } \\
\text { acetabular osteotomy was } \\
\text { performed. }\end{array}$ & Two years & $\begin{array}{c}\text { Recurrence of } \\
\text { subluxation at } 6 \text { weeks } \\
\text { after surgery. Greater } \\
\text { trochanter distal } \\
\text { transfer was then } \\
\text { performed. }\end{array}$ \\
\hline \multirow[b]{2}{*}{$\begin{array}{l}\text { Jellicoe et al., } \\
2009 \text { [7] }\end{array}$} & \multirow[b]{2}{*}{ Two } & $\begin{array}{l}\text { Nine } \\
\text { years }\end{array}$ & Female & $\begin{array}{l}\text { Circumferential } \\
\text { femoral neck } \\
\text { and floor of } \\
\text { acetabulum. }\end{array}$ & $\begin{array}{l}\text { Excision through anterolateral } \\
\text { approach and surgical hip } \\
\text { dislocation. No pelvic } \\
\text { osteotomy was performed. }\end{array}$ & Two years & \multirow[b]{2}{*}{ Not reported. } \\
\hline & & 11 years & Male & $\begin{array}{l}\text { Cotyloid } \\
\text { foramen. }\end{array}$ & $\begin{array}{l}\text { Excision through } \\
\text { transtrochanteric approach } \\
\text { and surgical hip dislocation. } \\
\text { No pelvic osteotomy was } \\
\text { performed. }\end{array}$ & $\begin{array}{l}\text { Three } \\
\text { years }\end{array}$ & \\
\hline $\begin{array}{l}\text { Ofiram and } \\
\text { Porat, } 2004 \text { [9] }\end{array}$ & One & 16 years & Female & $\begin{array}{l}\text { Circumferential } \\
\text { at the femoral } \\
\text { neck and also at } \\
\text { the acetabular } \\
\text { floor. }\end{array}$ & $\begin{array}{l}\text { Excision through } \\
\text { Smith-Peterson approach and } \\
\text { intraoperative hip } \\
\text { subluxation. No pelvic } \\
\text { osteotomy was performed. }\end{array}$ & $\begin{array}{l}\text { Three } \\
\text { years }\end{array}$ & Not reported. \\
\hline
\end{tabular}

Case 2. This four-year-old female was referred to the authors' center for a recent diagnosis of HME. On her first visit, she had no complaints and her examination was unremarkable apart from palpable osteochondromas in the upper extremities and distal femora. Radiographs revealed a left femoral neck osteochondroma with bilateral coxa valga (left > right), a left dysplastic hip (CEA 7 degrees), and left hip subluxation (Figure 2(a)). At one year of follow-up, progressive left hip subluxation $(\mathrm{CEA}=0$ ) was noted (Figures $2(\mathrm{~b})$ and $2(\mathrm{c})$ ). Consequently, a left femoral varus derotational osteotomy with partial excision of the osteochondroma was performed by the treating surgeon (T.B) through the lateral approach. This was followed by application of a paediatric dynamic hip screw (DHS). The patient was able to walk with a normal gait without any associated pain at 1-year followup and by the 2nd year she was able to participate in sports. Her flexion and internal rotation improved significantly on subsequent follow-ups. However, external rotation and abduction of the left hip did not improve. Four years postoperatively, she was noted to have a restricted ROM in terms of hip abduction, external rotation, and flexion. Pelvic radiographs showed significant recurrence of the left hip osteochondroma with persistent left acetabular dysplasia and worsening left hip subluxation (Figure 2(d)). At this time she underwent a proximal femoral varus osteotomy and extensive excision of the left femoral neck osteochondroma through the lateral approach. In addition, a modified Dega osteotomy $[28,29]$ was performed through a Smith-Petersen approach. Postoperatively, the patient was placed in a left lower extremity hip spica cast and remained nonweight bearing for six weeks. The cast was removed six weeks after surgery and physiotherapy was initiated. At ten months follow-up, she had persistent weakness of her abductors and hardware related pain over her left proximal femur. Pelvic radiographs showed good femoral head coverage (CEA 35 degrees) and a healed osteotomy (Figure 2(e)). However, partial osteonecrosis of the femoral head was noted. At oneyear follow-up, her Trendelenburg gait persisted and she reported pain at the prominent hardware site. Her ROM and radiographs were unchanged from previous examination. At this time point, hardware removal was planned. At six months after removal, she was ambulating with a mild Trendelenburg. Her trochanteric pain was reported to be much better than before. 


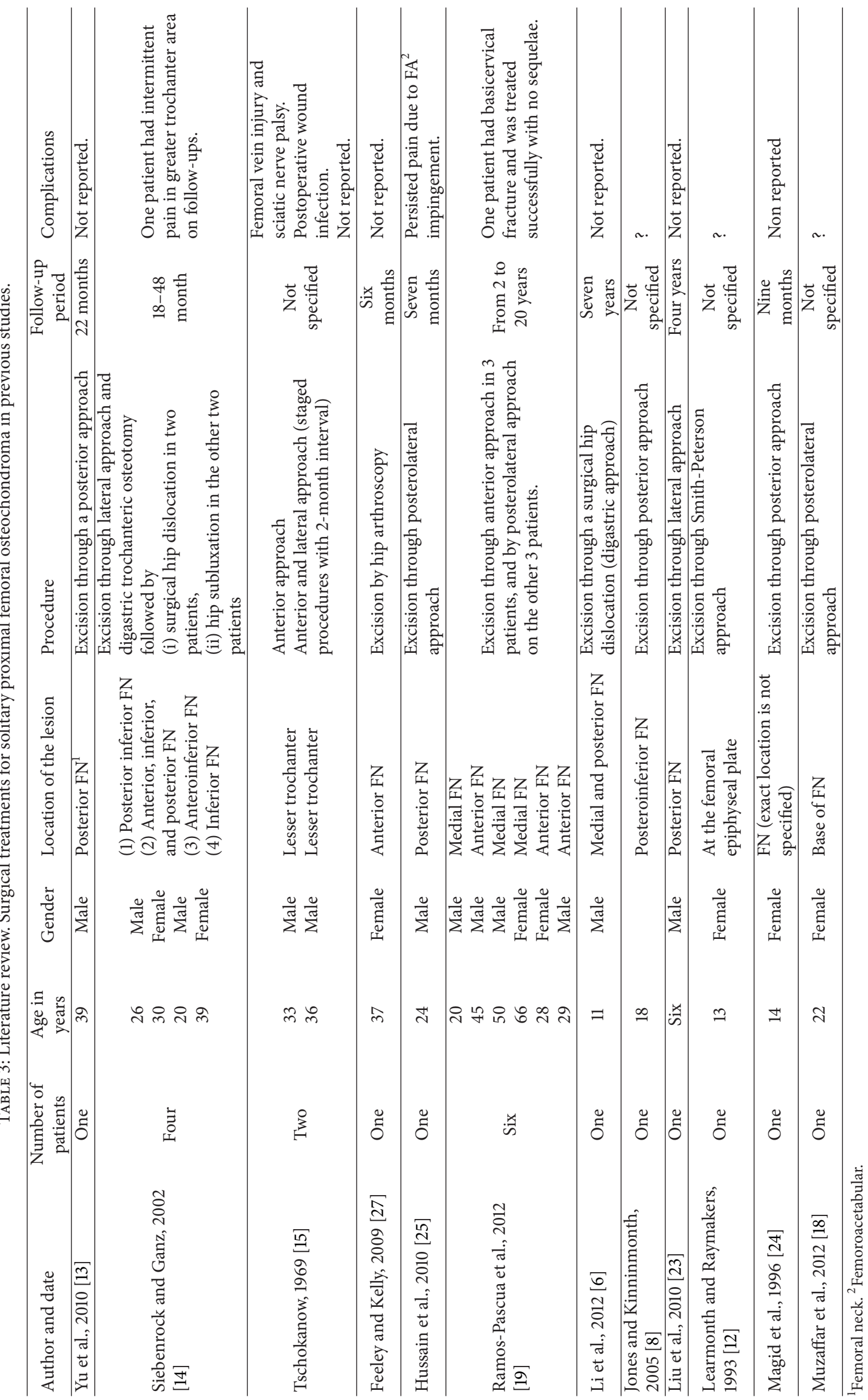




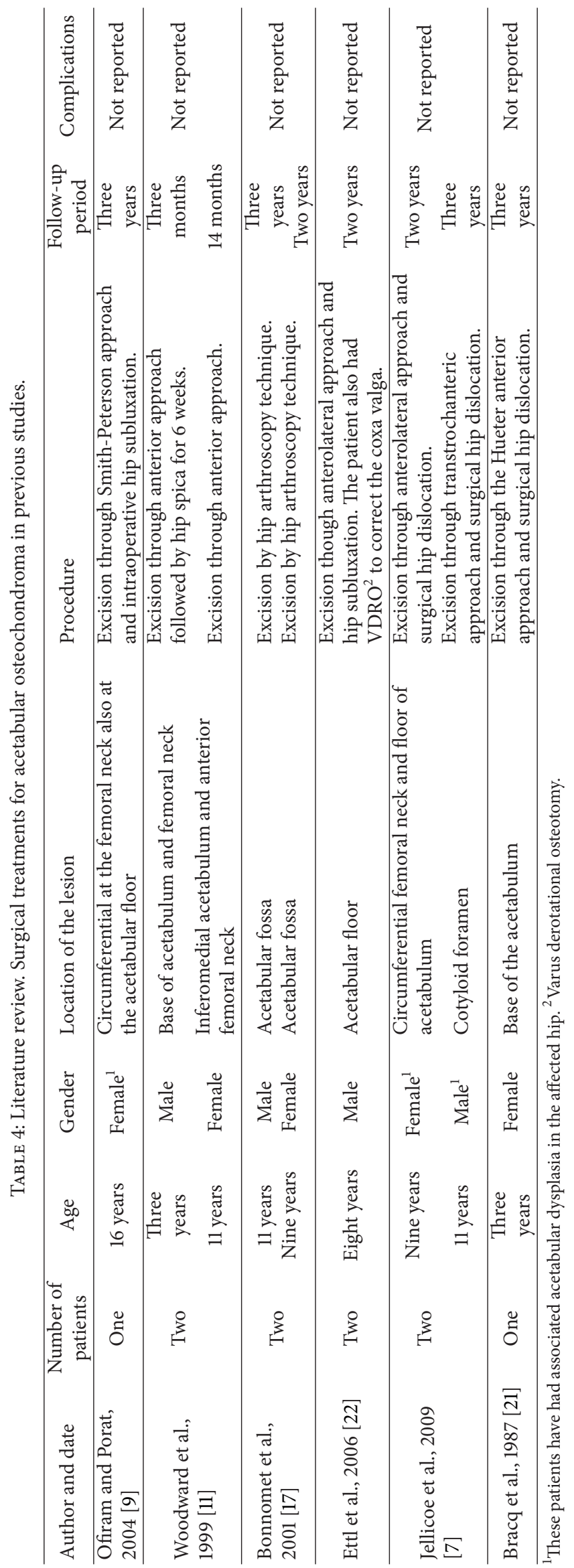




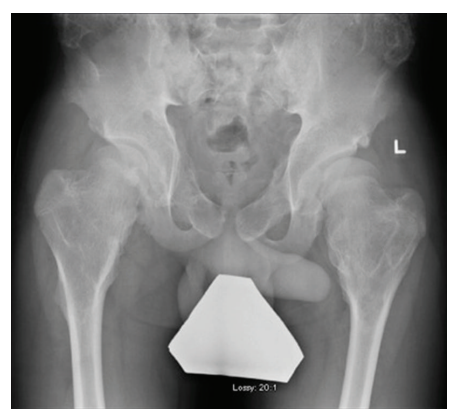

(a)

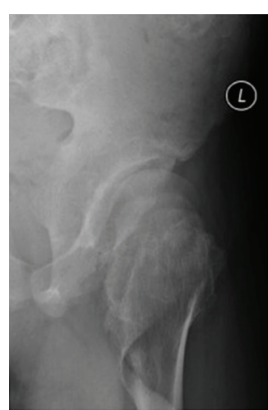

(b)

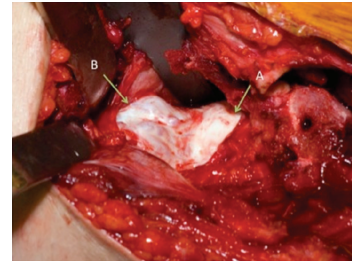

(c)

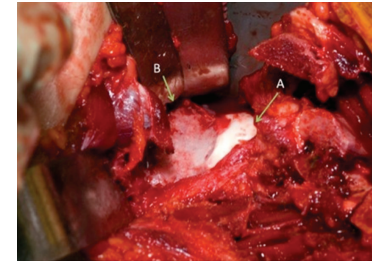

(d)

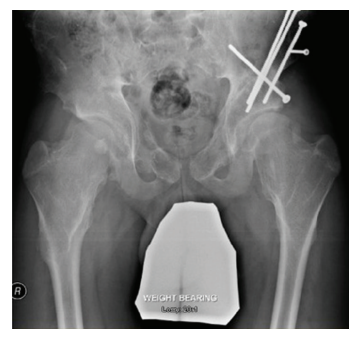

(e)

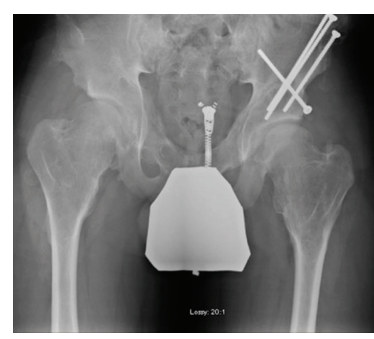

(f)

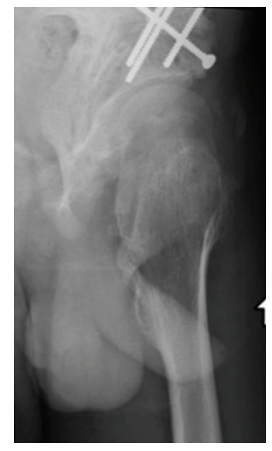

(g)

Figure 1: (a) Preoperative anteroposterior pelvic radiograph. (b) Preoperative false profile view showing poor anterior femoral head coverage. (c) Intraoperative images showing the location of the femoral head (arrow A) and the femoral neck osteochondroma (arrow B). (d) Postpartial excision of osteochondroma (arrow B) and the location of the femoral head (arrow A). (e) Anteroposterior pelvic radiograph at 1-year followup. (f) Anteroposterior pelvic radiograph at 18 months of follow-up. (g) False profile pelvic radiograph at 18 months of follow-up showing improved anterior coverage.

Case 3. This thirteen-year-old female known for HME was referred to our center for left groin pain with a locking sensation. She had undergone multiple previous surgeries in the lower extremities for excision of osteochondromas. On examination, she had limited flexion, abduction, and internal/external rotation. The radiographs showed bilateral acetabular dysplasia (CEA: left $=-5$ degrees/right $=+10$ degrees) with an increased left femoral neck width secondary to osteochondromas (Figure 3(a)). Magnetic resonance imaging showed a large sessile osteochondroma in the acetabular fossa (Figure 3(b)). The treating surgeon (M.L) has performed a left acetabular Shelf procedure and femoral neck osteoplasty through the anterior approach. The acetabular osteochondroma was not excised. Postoperatively, the patient was kept partial weight bearing for 6 weeks with ROM exercises as tolerated. At three-year follow-up, the patient reported no left hip pain and the ROM had improved significantly. Pelvic radiographs showed good femoral head coverage $(\mathrm{CEA}=40$ degrees) (Figure 3(c)).

\section{Discussion}

The presented cases have illustrated successful excision of femoral neck osteochondromas and treatment of acetabular dysplasia and poor femoral head coverage through three different surgical treatments. A strong relationship between HME and the occurrence of acetabular dysplasia has been reported in the literature [5]. It has been hypothesized that acetabular dysplasia occurs in HME secondary to biomechanical alterations in the hip joint. The osteochondromas can result in abnormal mechanical forces that may drive the dysplasia. It has also been hypothesized that coxa valga may contribute to the dysplasia $[5,26,30]$. There is no consensus in the current literature with respect to surgical treatment for hip osteochondromas when associated with acetabular dysplasia (Table 2). Malagón resected two femoral neck osteochondromas in two paediatric patients (8 and 9 years old) with acetabular dysplasia [5]. He also performed bilateral staged Chiari procedures along with varus femoral derotational osteotomies. Although satisfactory results were achieved, one patient had persisted hip pain and restricted ROM. Felix et al. resected bilateral femoral neck osteochondromas in a 12-year-old female patient who also had acetabular dysplasia. Bilateral staged resections, steel osteotomies, and proximal femoral varus osteotomies were performed through the posterior approach [10]. At 3 years of follow-up, no complications were reported. Shinozaki et al. resected a femoral neck osteochondroma in a 30 -year-old male patient who had a dysplastic hip [16]. The authors resected the lesion through the anterior approach and posterior approach. A rotational osteotomy was also performed. At 6 weeks of follow-up, recurrence of hip subluxation was observed and the greater trochanter was transferred distally. Ofiram and Porat have reported a female patient (16 years old) who had 


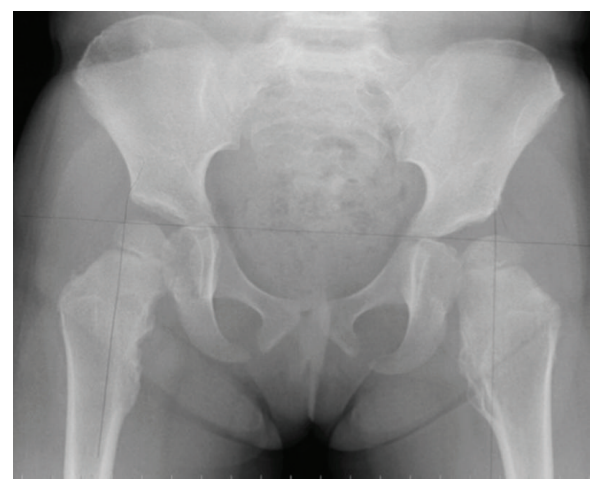

(a)

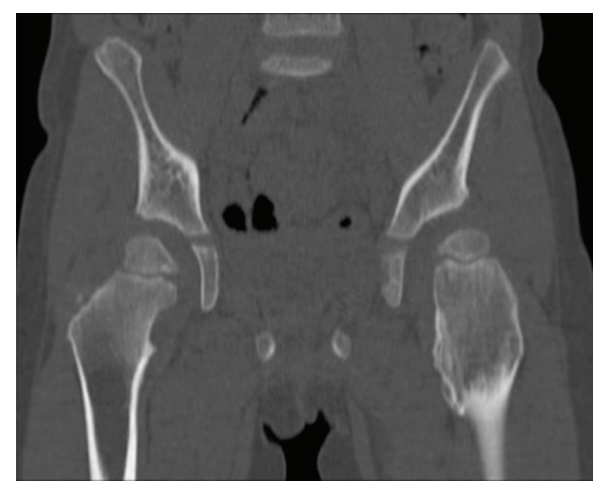

(c)

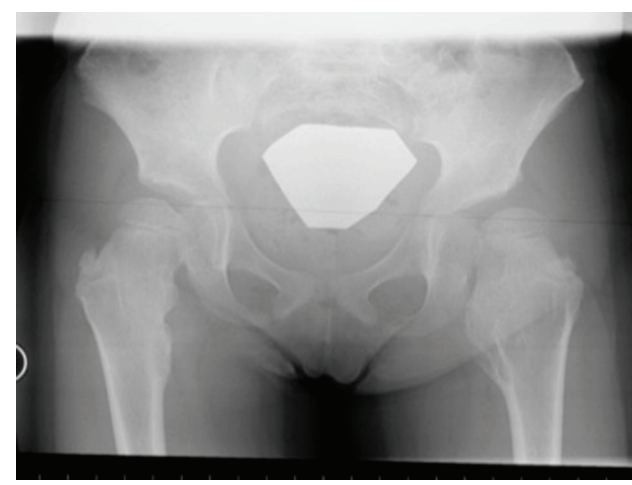

(b)

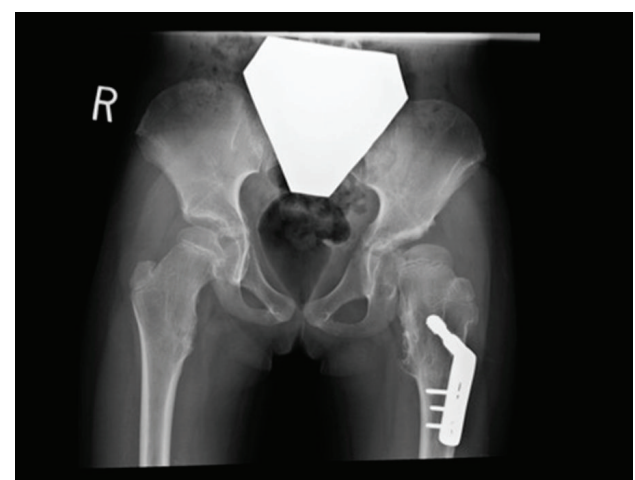

(d)

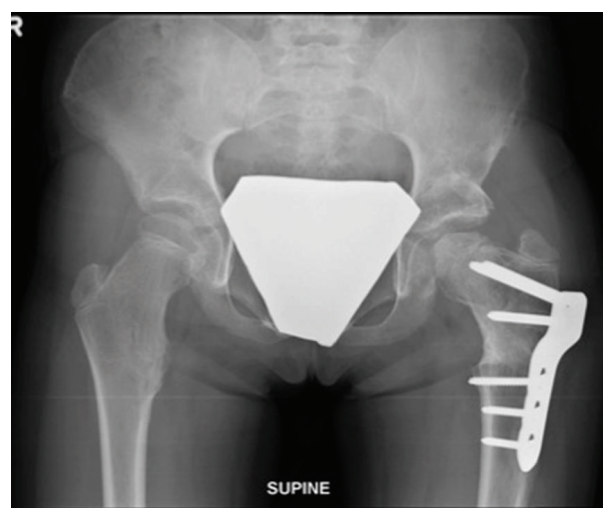

(e)

FIGURE 2: (a) Anteroposterior pelvic radiograph at initial presentation. (b) Anteroposterior pelvic radiograph and (c) Computed tomography of the pelvis at one-year follow-up. (d) Anteroposterior pelvic radiograph 4 years after left femoral varus derotational osteotomy (VDRO) with partial excision of the osteochondroma. (e) Anteroposterior pelvic radiograph ten months after performing the second VDRO, modified Dega osteotomy, and extensive excision of femoral neck osteochondroma. Partial left femoral head necrosis is also noted.

an osteochondroma at the femoral neck (circumferential) and floor of acetabulum in association with acetabular dysplasia [9]. They excised the lesion through the anterior approach with intraoperative hip subluxation. No pelvic procedure was performed, and the patient remains asymptomatic at 3 years of follow-up. In conclusion, these case reports indicate that a combined approach of osteochondroma excision and pelvic osteotomy is feasible and tolerated well in the short term. One question that remains is whether or not early surgical excision of these lesions may prevent acetabular dysplasia. Jellicoe et al. [7] reported two paediatric patients (aged 9 and 11 years) with acetabular osteochondromas and acetabular dysplasia that were successfully treated with intraoperative excision of the lesions by surgically dislocating the hip. At 2 years of follow-up, although the patients had no symptoms, residual acetabular dysplasia and growth disturbance were found. The authors concluded that excision of osteochondromas appears not to prevent or improve acetabular dysplasia. Despite their conclusion, we still feel that early excision of the osteochondromas can prevent acetabular dysplasia when performed at young age. Theoretically speaking, if performed while the acetabulum still has significant remodelling 


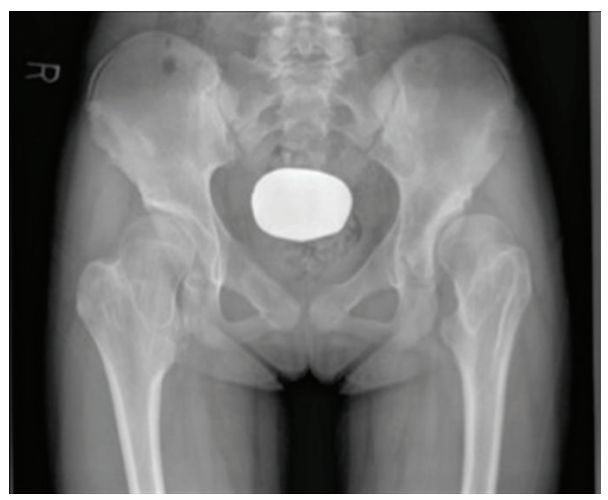

(a)

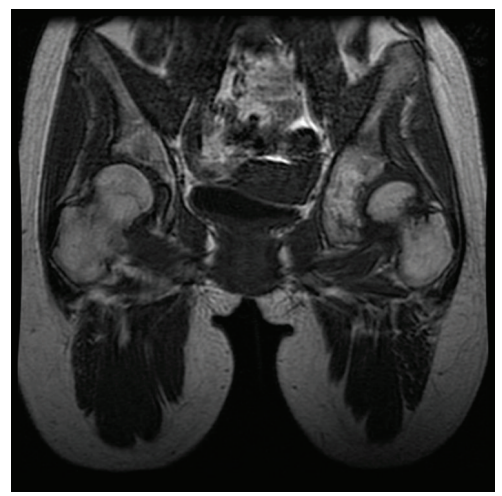

(b)

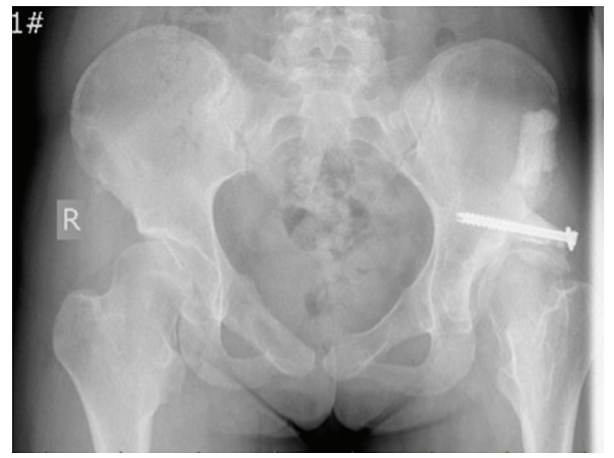

(c)

FIgURE 3: (a) Anteroposterior pelvic radiograph at initial presentation. (b) Magnetic resonance imaging showing a large sessile osteochondroma within the left acetabular fossa. (c) Anteroposterior radiograph of the pelvis 3 years after the left acetabular Shelf procedure and femoral neck osteoplasty.

potential, osteochondroma excision should affect acetabular development. Furthermore, acetabular dysplasia is often asymptomatic. Therefore, we strongly recommend a routine radiographic pelvic survey at the time of diagnosis of $\mathrm{HME}$ so that early detection of the osteochondroma can be made and treatment can be recommended. Unfortunately, there is no data available to recommend on the frequency of radiographic surveillance.

Osteochondromas can occur as solitary lesions in the proximal femur and these typically are not associated with acetabular dysplasia or coxa valga. However, many problems can arise from these lesions such as labral tears, nerve compression, hip dislocation, external snapping hip, and malignant transformation in $0.4-2 \%$ of patients $[8,13,19$, $20,27]$. A variety of surgical techniques have been reported in the literature for these solitary lesions without dysplasia (Table 3). The main concerns for surgical resection of femoral neck and peritrochanteric osteochondromas are exposure and femoral head vascularity. In our report (Case 2), we believe that the multiple surgeries around the hip might have put the femoral head blood supply at risk and contributed to the partial osteonecrosis. Siebenrock and Ganz have described the lateral approach to the hip with surgical hip dislocation to allow access and adequate exposure of the femoral neck while preserving the vascular supply [14]. They presented four adult patients with successful resection of femoral neck osteochondromas located in posterior, inferior, and anterior regions of the femoral neck. Li et al. [6] have echoed these results utilizing the same technique for the resection of a posteromedial femoral neck osteochondroma in one paediatric case. Using both anterior and posterolateral approaches, Ramos-Pascua et al. have successfully excised femoral neck osteochondromas in 6 patients without dislocating or subluxating the hip [19]. These patients had good to excellent results based on the Musculoskeletal Tumour Society (MSTS) scale. Tschokanow [15] reported on two adult cases of lesser trochanter osteochondromas in which one patient had an excision through the anterior approach and was complicated by femoral vein laceration and sciatic nerve palsy. The second patient underwent a two-staged procedure (through anterior and lateral approach) with no reported complications. Recently, Feely and Kelly have proposed the use of hip arthroscopy for excising small osteochondromas in the femoral neck [27]. Taken together, the literature review failed to conclude a uniform treatment for these lesions. Until further data is published, surgeons treating these lesions must carefully plan surgery such that a safe and adequate resection can be carried out in an effective manner utilizing the surgical approach they feel most comfortable with while paying particular attention to femoral head vascularity. In addition, the exact location of the lesion should be defined preoperatively to help develop a surgical plan and the use 
of intraoperative fluoroscopy can be helpful in localizing the lesion and in verifying adequate resection.

Few reports in the literature have described the occurrence of osteochondromas in the acetabulum. The majority of the reported cases underwent surgical hip dislocation/subluxation to excise the acetabular lesion (Table 4). The advantage of using the surgical dislocation approach is to gain full access to such lesions. Woodward et al. reported on two paediatric patients with acetabular and femoral neck osteochondromas excised through an anterior approach without the need for intraoperative hip dislocation [11]. Using hip arthroscopy, Bonnomet et al. successfully excised a small acetabular osteochondroma in an 11-yearold patient with HME [17]. In our report (Case 3), we did not excise the acetabular osteochondroma as it was large and sessile. Surgical excision of such large sessile lesions will result in significant acetabular cartilage and bone deficiency. Therefore, we chose to leave the acetabular lesion and treat the dysplasia by performing a Shelf augmentation procedure and excision of the femoral neck osteochondroma. Preoperative hinge abduction and the questionable quality of the remaining cartilage made periacetabular rotational osteotomy a suboptimal option.

In conclusion, the literature review failed to conclude a uniform treatment for patients with hip joint osteochondromas with or without hip dysplasia. The three reported cases illustrate the successful excision of femoral neck osteochondromas and treatment of acetabular dysplasia through three different surgical treatments. In HME patients, we believe that early excision of osteochondromas can prevent the occurrence of acetabular dysplasia. Therefore, we recommend a routine radiographic pelvic survey in HME patients at the time of diagnosis for early detection of osteochondromas in the hip. Our results suggest the need for a multi-institutional prospective study for the natural history of hip pain and arthrosis and the surgical treatment of hip joint osteochondromas and also for determining the frequency of radiographic pelvic surveys in HME patients.

\section{Conflict of Interests}

No benefits in any form have been received or will be received from a commercial party related directly or indirectly to the subject of this paper. The authors declare that there is no conflict of interests regarding the publication of this paper.

\section{References}

[1] H. A. Peterson, "Multiple hereditary osteochondromata," Clinical Orthopaedics and Related Research, no. 239, pp. 222-230, 1989.

[2] F. Shapiro, S. Simon, and M. J. Glimcher, "Hereditary multiple exostoses. Anthropometric, roentgenographic, and clinical aspects," The Journal of Bone and Joint Surgery. American, vol. 61, no. 6, pp. 815-824, 1979.

[3] G. A. Schmale, E. U. Conrad III, and W. H. Raskind, "The natural history of hereditary multiple exostoses," The Journal of Bone and Joint Surgery. American, vol. 76, no. 7, pp. 986-992, 1994.
[4] P. K. Cheung, C. McCormick, B. E. Crawford, J. D. Esko, F. Tufaro, and G. Duncan, "Etiological point mutations in the hereditary multiple exostoses gene EXT1: a functional analysis of heparan sulfate polymerase activity," American Journal of Human Genetics, vol. 69, no. 1, pp. 55-66, 2001.

[5] V. Malagón, "Development of hip dysplasia in hereditary multiple exostosis," Journal of Pediatric Orthopaedics, vol. 21, no. 2, pp. 205-211, 2001.

[6] M. Li, T. Luettringhaus, K. R. Walker, and P. A. Cole, "Operative treatment of femoral neck osteochondroma through a digastric approach in a pediatric patient: a case report and review of the literature," Journal of Pediatric Orthopaedics B, vol. 21, no. 3, pp. 230-234, 2012.

[7] P. Jellicoe, J. Son-Hing, S. Hopyan, and G. H. Thompson, "Surgical hip dislocation for removal of intraarticular exostoses: report of two cases," Journal of Pediatric Orthopaedics, vol. 29, no. 4, pp. 327-330, 2009.

[8] B. G. Jones and A. W. G. Kinninmonth, "Low-energy hip dislocation in the young," Journal of Trauma, vol. 58, no. 3, pp. 638-639, 2005.

[9] E. Ofiram and S. Porat, "Progressive subluxation of the hip joint in a child with hereditary multiple exostosis," Journal of Pediatric Orthopaedics B, vol. 13, no. 6, pp. 371-373, 2004.

[10] N. A. Felix, J. M. Mazur, and E. A. Loveless, "Acetabular dysplasia associated with hereditary multiple exostoses: a case report," The Journal of Bone and Joint Surgery. British, vol. 82, no. 4, pp. 555-557, 2000.

[11] M. N. Woodward, K. E. Daly, R. D. A. Dodds, and J. A. Fixsen, "Subluxation of the hip joint in multiple hereditary osteochondromatosis: report of two cases," Journal of Pediatric Orthopaedics, vol. 19, no. 1, pp. 119-121, 1999.

[12] D. J. A. Learmonth and R. Raymakers, "Osteochondroma of the femoral neck secondary to a slipped upper femoral epiphysis," Archives of Orthopaedic and Trauma Surgery, vol. 112, no. 2, pp. 106-107, 1993.

[13] K. Yu, J. P. Meehan, A. Fritz, and A. A. Jamali, "Osteochondroma of the femoral neck: a rare cause of sciatic nerve compression," Orthopedics, vol. 33, no. 8, 2010.

[14] K.-A. Siebenrock and R. Ganz, "Osteochondroma of the femoral neck," Clinical Orthopaedics and Related Research, no. 394, pp. 211-218, 2002.

[15] K. Tschokanow, "2 cases of osteochondroma of the femur neck," Beitrage zur Orthopadie und Traumatologie, vol. 16, no. 12, pp. 751-752, 1969.

[16] T. Shinozaki, H. Watanabe, J. Inoue, and T. Ogiwara, "Rotational acetabular osteotomy in a dysplastic hip with femoral neck osteochondromas," Orthopedics, vol. 21, no. 5, pp. 588-590, 1998.

[17] F. Bonnomet, P. Clavert, F. Z. Abidine, P. Gicquel, J. M. Clavert, and J. F. Kempf, "Hip arthroscopy in hereditary multiple exostoses: a new perspective of treatment," Arthroscopy, vol. 17, no. 9, p. E40, 2001.

[18] N. Muzaffar, N. Bashir, A. Baba, A. Ahmad, and N. Ahmad, "Isolated osteochondroma of the femoral neck presenting as hip and leg pain. A case study," Ortopedia, Traumatologia, Rehabilitacja, vol. 14, no. 2, pp. 183-187, 2012.

[19] L. Ramos-Pascua, S. Sánchez-Herráez, J. Alonso-Barrio, and A. Alonso-León, "Solitary proximal end of femur osteochondroma. An indication and result of the en bloc resection without hip luxation," Revista Española de Cirugía Ortopédica y Traumatología, vol. 56, no. 1, pp. 24-31, 2012 (Spanish). 
[20] S. Inoue, Y. Noguchi, T. Mae, S. Rikimaru, and S. Hotokezaka, "An external snapping hip caused by osteochondroma of the proximal femur," Modern Rheumatology, vol. 15, no. 6, pp. 432434, 2005.

[21] H. Bracq, L. Guibert, and B. Fremond, "A case of exostosis of the base of the acetabulum in a child with multiple exostoses," Revue de Chirurgie Orthopedique et Reparatrice de l'Appareil Moteur, vol. 73, no. 6, pp. 501-504, 1987 (French).

[22] V. Ettl, S. Siebenlist, O. Rolf, S. Kirschner, and P. Raab, "Intraacetabular localisation of an osteochondroma causing subluxation of the hip joint-a rare entity in children with multiple hereditary exostoses," Zeitschrift für Orthopädie und Ihre Grenzgebiete, vol. 144, no. 1, pp. 87-90, 2006 (German).

[23] Z. J. Liu, Q. Zhao, and L. J. Zhang, "Extraskeletal osteochondroma near the hip: a pediatric case," Journal of Pediatric Orthopaedics B, vol. 19, no. 6, pp. 524-528, 2010.

[24] D. Magid, P. D. Sponseller, and E. McCarthy, "Intoeing in a 14year-old girl," Clinical Orthopaedics and Related Research, no. 325, pp. 322-325, 1996.

[25] W. Hussain, R. Avedian, M. Terry, and T. Peabody, "Solitary osteochondroma of the proximal femur and femoral acetabular impingement," Orthopedics, vol. 33, no. 1, p. 51, 2010.

[26] D. E. Porter, M. K. Benson, and G. A. Hosney, "The hip in hereditary multiple exostoses," The Journal of Bone and Joint Surgery. British, vol. 83, no. 7, pp. 988-995, 2001.

[27] B. Feeley and B. Kelly, "Arthroscopic management of an intraarticular osteochondroma of the hip," Orthopedic Reviews, vol. 1, no. 1, article e2, 2009.

[28] A. Al-Ghamdi, J. S. Rendon, F. Al-Faya, N. Saran, T. Benaroch, and R. C. Hamdy, "Dega osteotomy for the correction of acetabular dysplasia of the hip: a radiographic review of 21 cases," Journal of Pediatric Orthopaedics, vol. 32, no. 2, pp. 113120, 2012.

[29] S. J. Mubarak, F. G. Valencia, and D. R. Wenger, "One-stage correction of the spastic dislocated hip. Use of pericapsular acetabuloplasty to improve coverage," The Journal of Bone and Joint Surgery. American, vol. 74, no. 9, pp. 1347-1357, 1992.

[30] T. A. M. El-Fiky, W. Chow, Y. H. Li, and M. To, "Hereditary multiple exostoses of the hip," Journal of Orthopaedic Surgery, vol. 17, no. 2, pp. 161-165, 2009. 


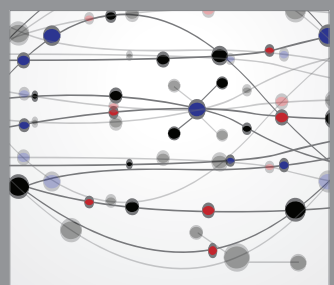

The Scientific World Journal
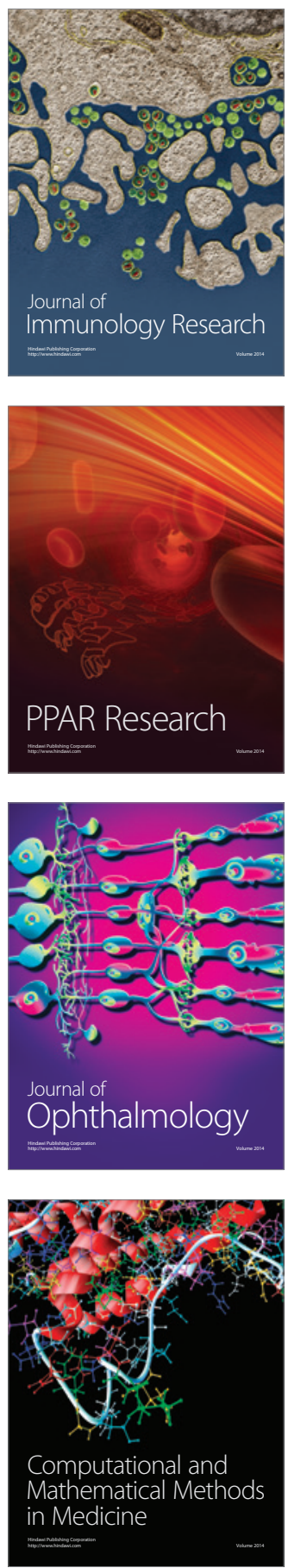

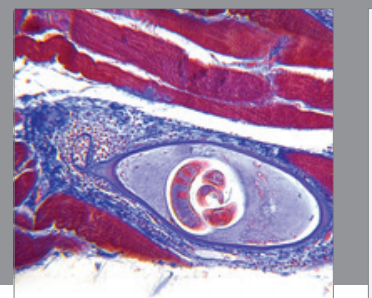

Gastroenterology

Research and Practice
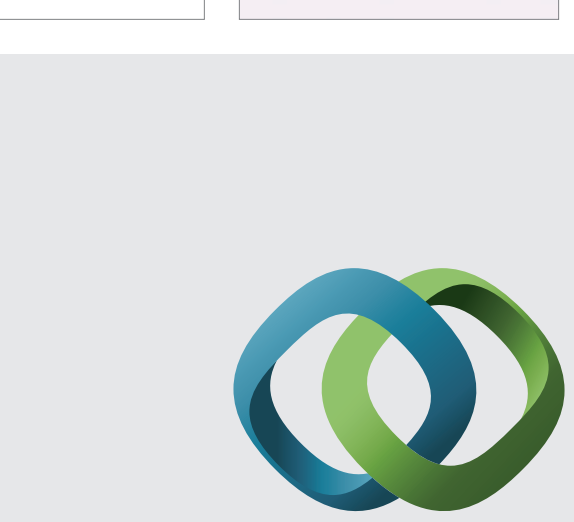

\section{Hindawi}

Submit your manuscripts at

http://www.hindawi.com
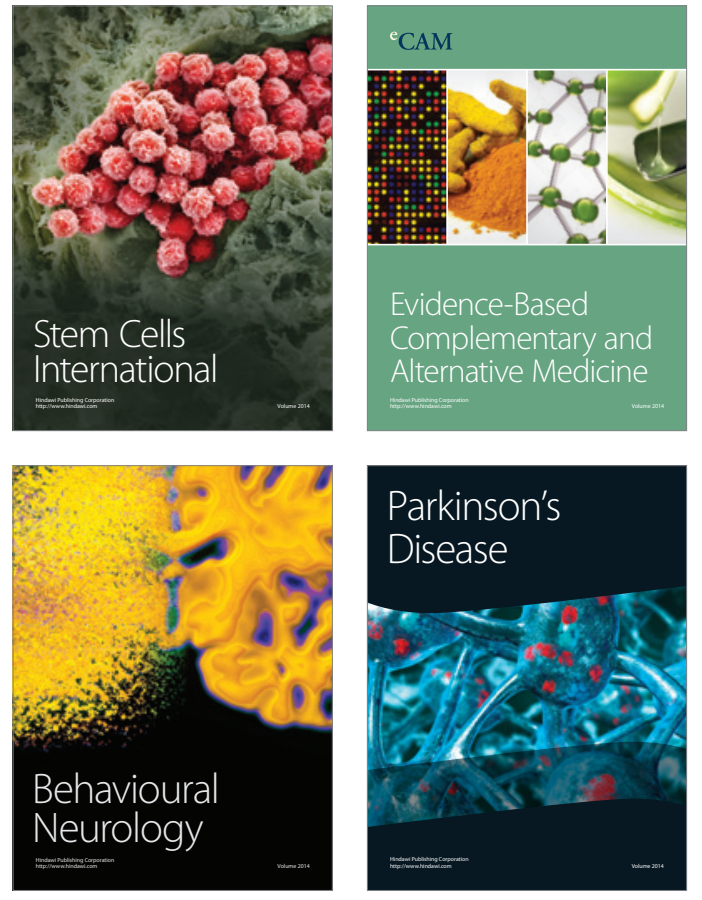
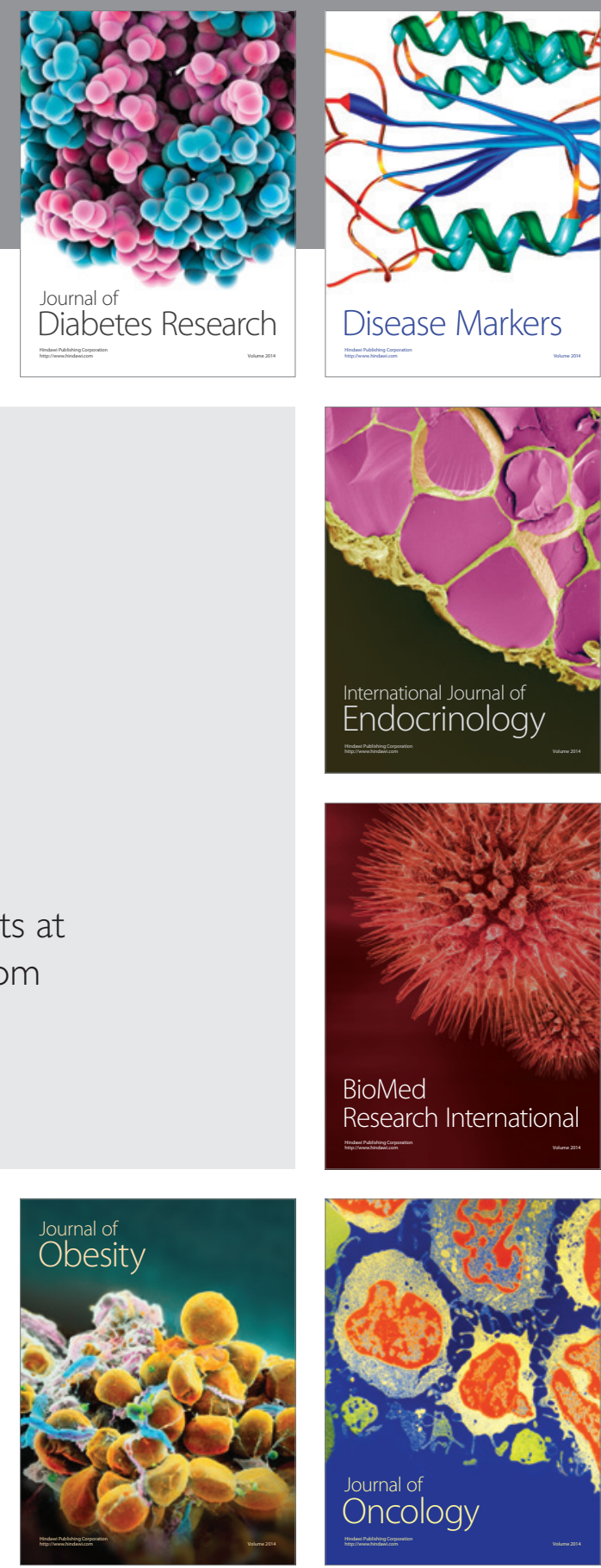

Disease Markers
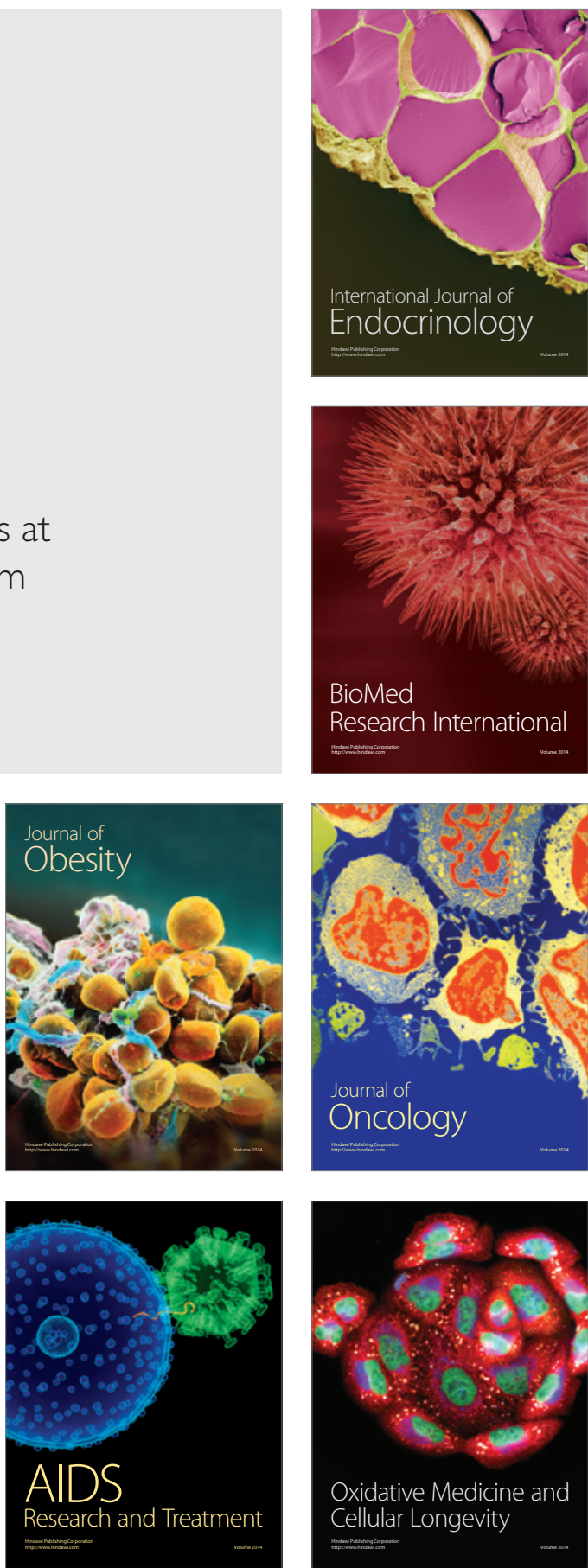